\title{
Strangulation Caused by a Small Bowel Epiploic Appendage: Report of a Case
}

\author{
Hiroshi Nemoto ${ }^{a}$ Yasuo Yoshizawa $^{a}$ Kenji Hibi ${ }^{a}$ \\ Mitsuo Saito ${ }^{a}$ Kazuyoshi Ishibashi ${ }^{a}$ Yutaka Sanada $^{a}$ \\ Genshu Tate ${ }^{b}$
}

Departments of a Surgery and bSurgical Pathology, Showa University Fujigaoka

Hospital, Yokohama, Japan

\section{Key Words}

Epiploic appendage strangulation $\cdot$ Small bowel $\cdot$ Volvulus

\begin{abstract}
While many recent cases of colonic epiploic appendage causing acute abdomen have been reported, such appendages of the small bowel are extremely rare. We present a 59year-old woman in whom a small bowel epiploic appendage caused volvulus. She presented with abdominal pain and vomiting in the absence of previous abdominal operations. A diagnosis of small bowel obstruction from strangulation was made. Laparotomy disclosed bloody peritoneal fluid and a closed loop of strangulated small intestine. An adherent band composed of an epiploic appendage and intestine had completely encircled a loop of jejunum, leading to obstruction. This band was released, and approximately $80 \mathrm{~cm}$ of gangrenous bowel was resected. Four epiploic appendages $5-6 \mathrm{~cm}$ in length were attached to the ileum at the mesenteric border, beginning at a point $70 \mathrm{~cm}$ proximal to the terminal ileum.
\end{abstract}

\section{Introduction}

Many colonic epiploic appendages have been reported recently as a cause of acute abdomen. Such appendages of the small bowel are extremely rare. We present a patient in whom a small bowel epiploic appendage caused volvulus.

\section{Case Report}

A 59-year-old woman was admitted to our hospital in March 2004 because of a 1-day history of worsening vomiting and epigastric pain. Her medical history included angina pectoris but no previous 
abdominal operations. On examination the patient was afebrile and in no acute distress. Pulse rate was $61 / \mathrm{min}$. Mild epigastric tenderness was elicited. Initially diagnosed with acute gastroenterocolitis, the patient was given intravenous fluid. Gradually worsening colicky pain was followed by abdominal distention. On the second hospital day physical examination disclosed tenderness and guarding in the lower abdominal area. Hemoglobin fell from 12.9 to $8.3 \mathrm{mg} / \mathrm{dl}$. Abdominal computed tomography (CT) showed ascites and an abnormally dilated loop of small bowel, which was not enhanced upon administration of contrast material. The preoperative diagnosis was small bowel obstruction by strangulation.

At laparotomy, bloody peritoneal fluid and a closed loop of strangulated intestine were found. An adherent band composed of an epiploic appendage and intestine had completely encircled a loop of jejunum, leading to obstruction (fig. 1). This band was released, and approximately $80 \mathrm{~cm}$ of gangrenous bowel was resected. A functional end-to-end anastomosis was performed. Four epiploic appendages 5-6 cm in length were attached to the ileum at the mesenteric border beginning at $70 \mathrm{~cm}$ proximal to the terminal ileum (fig. 2). We did not particularly pay attention to large bowel appendages. The postoperative course was uneventful. Histologically, the surgical specimen represented necrotic small bowel and four epiploic appendages composed of fat covered by serosa, showing congestion and hemorrhage (ig. 3 ). Infarction and necrosis were not revealed. Pathology was not found on the underlying small bowel mucosa.

\section{Discussion}

Epiploic appendages are fat-containing, visceral peritoneal herniations most often found along the two nonmesenteric teniae coli, occurring anywhere from the appendix to the peritoneal reflection [1]. They are more common along the transverse and sigmoid colon, with an average length of $3 \mathrm{~cm}$. The most common complications of epiploic appendages are inflammation and torsion [2]. While preoperative diagnosis of an acute abdomen caused by epiploic appendages is very difficult, some recent reports emphasize that CT findings of a fatty pericolic lesion with surrounding mesenteric inflammation can be helpful [3].

Occurrences of epiploic appendages along the small bowel are very rare, initially described by Mittal et al. [4] in a 43-year-old woman presenting with acute abdomen. At laparotomy, multiple epiploic appendages along the small bowel, including one along the distal jejunum, were completely necrotic and infarcted, having become adherent to the peritoneum in the right flank. To our knowledge, our patient represents only the second reported case of acute abdomen resulting from small bowel epiploic appendages. In this case, we think that only one of the four appendages had caused obstruction due to the adhesion to the small bowel or mesentery and that the three other appendages had not been involved.

Many colonic epiploic appendages causing acute abdomen have been reported [5]; in the colon, congenitally present appendages may enlarge in relation to normal structures, specifically the teniae. Small bowell appendages, on the other hand, are not known to occur congenitally. 
Fig. 1. Small bowel strangulation caused an adherent band composed of an epiploic appendage and intestine.

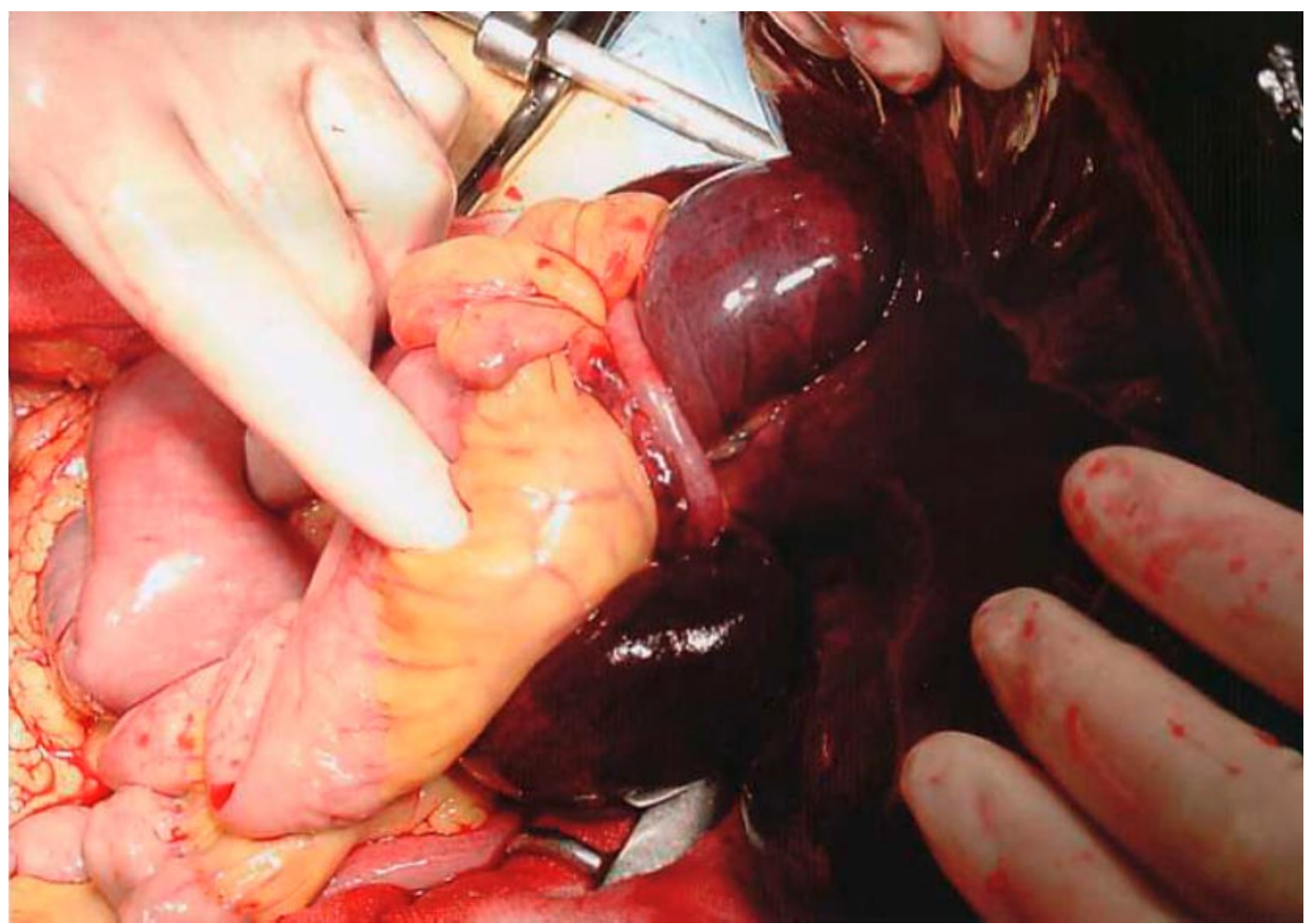

Fig. 2. Two epiploic appendages arose from the mesenteric border.

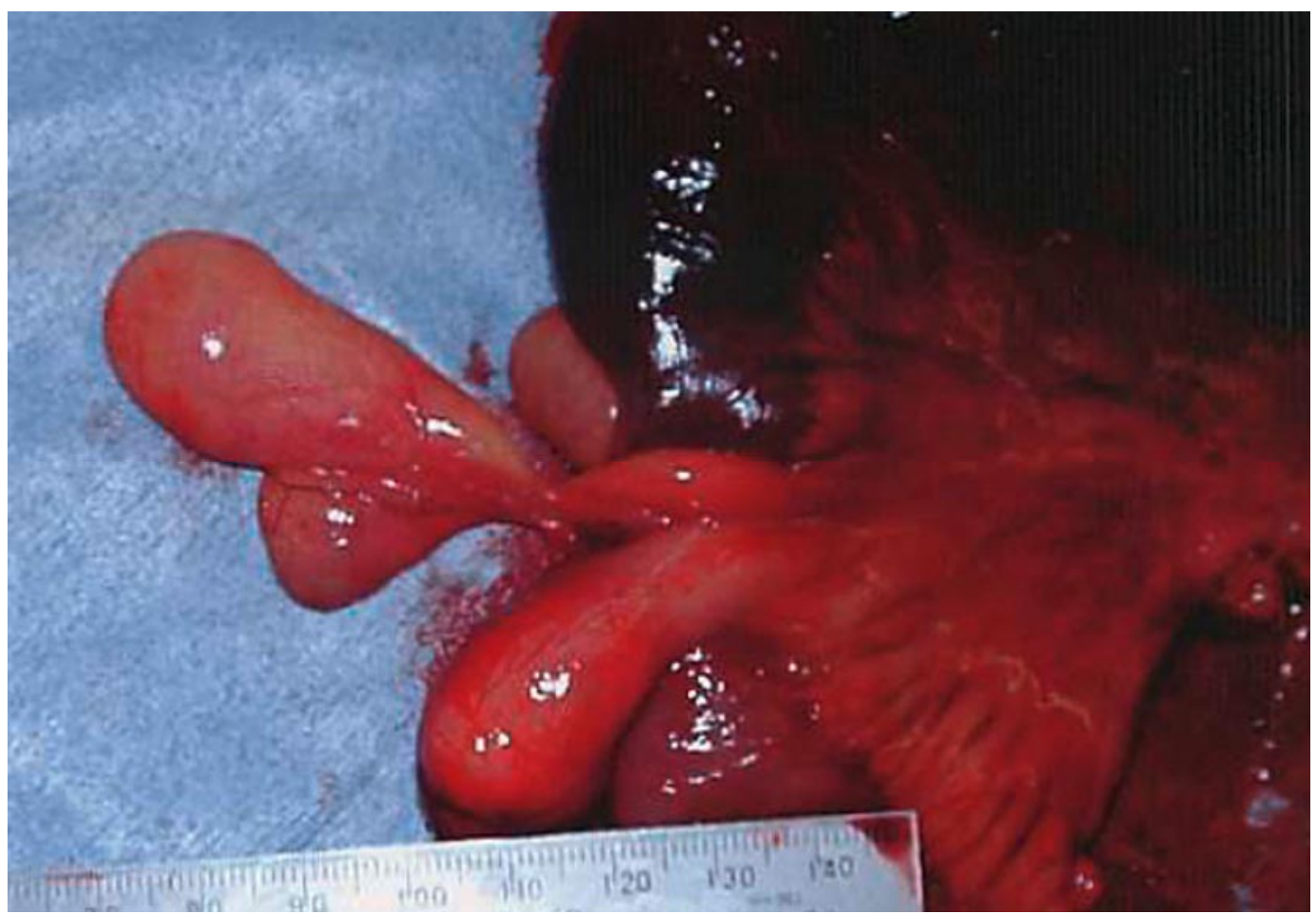


Fig. 3. Histologic examination showed that all epiploic appendages in the surgical specimen were composed mainly of fat and showed congestion and hemorrhage (hematoxylin and eosin, $\times 100$ ).

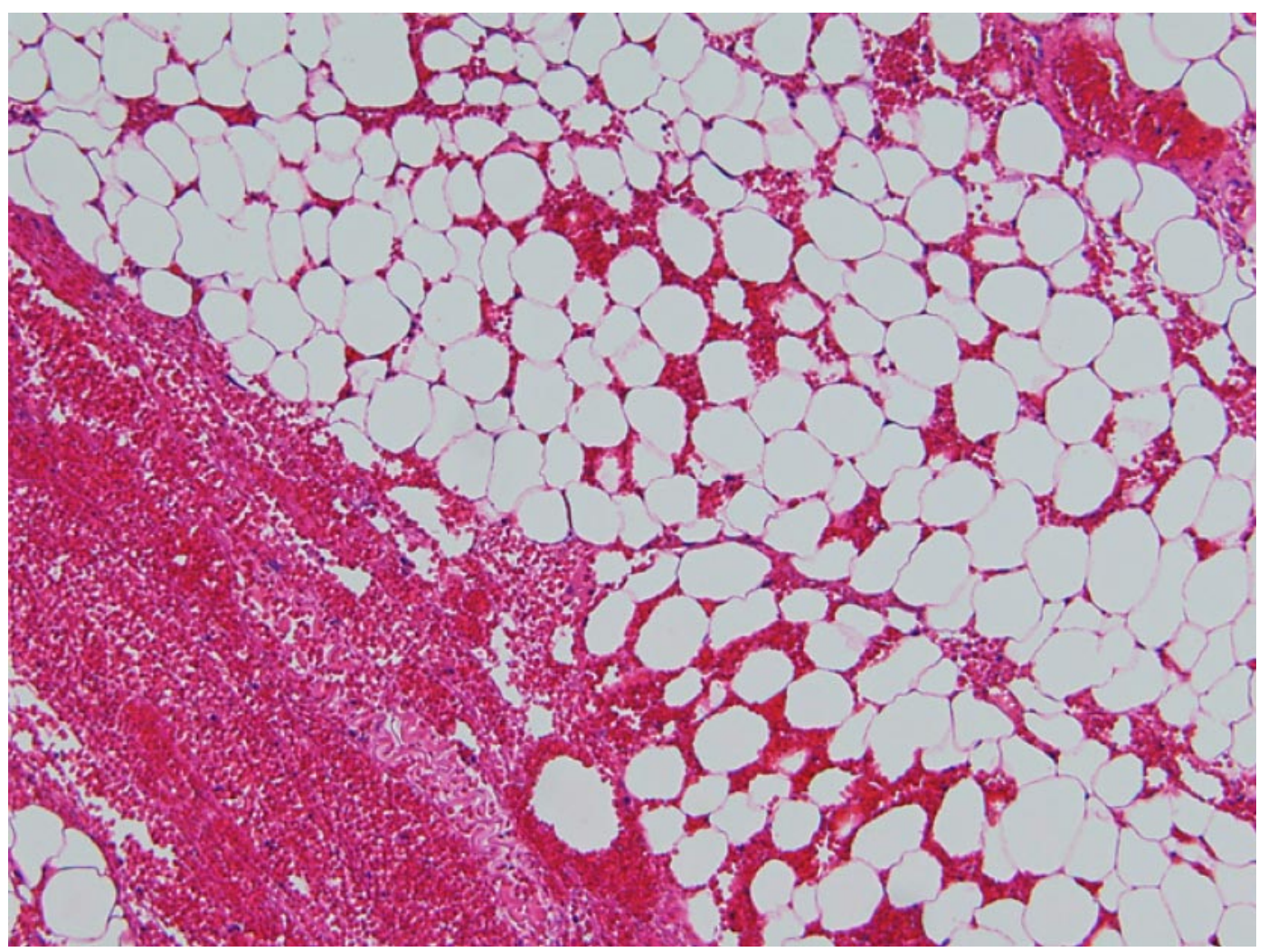




\section{References}

1 Thomas JH, Rosato FE, Patterson LT: Epiploic appendagitis. Surg Gynecol Obst 1974;138:23-25.

-2 Osadchy A, Shapiro-Feinberg M, Zissin R: Strangulated small bowel obstruction related to chronic torsion of an epiploic appendix: CT findings. Br J Radiol 2001;74:1062-1064.

3 Horton KM, Corl FM, Fishman EK: CT evaluation of the colon: inflammatory disease. Radiographics 2000;20:399-418.

$\checkmark 4$ Mittal VK, Pierce AK, Priestley JC, Cortez JA: Infarcted small bowel appendice epiploica: a cause of acute abdomen. Am J Protcol Gastroenterol Colon Rect Surg 1981;32:23-24.

5 Takahashi Y, Osada A, Okochi N: Two cases of small bowel obstruction due to an appendix epiploica (in Japanese with English abstract). Nihon Rinshogeka Gakkaishi (J Jpn Surg Assoc) 2005;66:2213. 